\title{
Benchmarking outcomes on multiple contextual levels in lean healthcare: a systematic review, development of a conceptual framework, and a research agenda
}

Elina Reponen ${ }^{1,2^{*}}$, Thomas G. Rundall', Stephen M. Shortell', Janet C. Blodgett ${ }^{1}$, Angelica Juarez ${ }^{1}$, Ritva Jokela ${ }^{2}$, Markku Mäkijärvi ${ }^{2}$ and Paulus Torkki ${ }^{3}$

\begin{abstract}
Background: Reliable benchmarking in Lean healthcare requires widely relevant and applicable domains for outcome metrics and careful attention to contextual levels. These levels have been poorly defined and no framework to facilitate performance benchmarking exists.

Methods: We systematically searched the Pubmed, Scopus, and Web of Science databases to identify original articles reporting benchmarking on different contextual levels in Lean healthcare and critically appraised the articles. Scarcity and heterogeneity of articles prevented quantitative meta-analyses. We developed a new, widely applicable conceptual framework for benchmarking drawing on the principles of ten commonly used healthcare quality frameworks and four value statements, and suggest an agenda for future research on benchmarking in Lean healthcare.

Results: We identified 22 articles on benchmarking in Lean healthcare on 4 contextual levels: intra-organizational (6 articles), regional (4), national (10), and international (2). We further categorized the articles by the domains in the proposed conceptual framework: patients (6), employed and affiliated staff (2), costs (2), and service provision (16). After critical appraisal, only one fifth of the articles were categorized as high quality.

Conclusions: When making evidence-informed decisions based on current scarce literature on benchmarking in healthcare, leaders and managers should carefully consider the influence of context. The proposed conceptual framework may facilitate performance benchmarking and spreading best practices in Lean healthcare. Future research on benchmarking in Lean healthcare should include international benchmarking, defining essential factors influencing Lean initiatives on different levels of context; patient-centered benchmarking; and system-level benchmarking with a balanced set of outcomes and quality measures.
\end{abstract}

Keywords: Lean management, Lean healthcare, Benchmarking, Context, Outcomes

\footnotetext{
* Correspondence: elina.reponen@hus.fi

${ }^{1}$ Center for Lean Engagement and Research in Healthcare, School of Public

Health, University of California, Berkeley, California, USA

${ }^{2}$ HUS Helsinki University Hospital, P.O.Box 760, 00029 Helsinki, Finland

Full list of author information is available at the end of the article
}

(c) The Author(s). 2021 Open Access This article is licensed under a Creative Commons Attribution 4.0 International License, which permits use, sharing, adaptation, distribution and reproduction in any medium or format, as long as you give appropriate credit to the original author(s) and the source, provide a link to the Creative Commons licence, and indicate if changes were made. The images or other third party material in this article are included in the article's Creative Commons licence, unless indicated otherwise in a credit line to the material. If material is not included in the article's Creative Commons licence and your intended use is not permitted by statutory regulation or exceeds the permitted use, you will need to obtain permission directly from the copyright holder. To view a copy of this licence, visit http://creativecommons.org/licenses/by/4.0/ The Creative Commons Public Domain Dedication waiver (http://creativecommons.org/publicdomain/zero/1.0/) applies to the data made available in this article, unless otherwise stated in a credit line to the data. 


\section{Background}

The healthcare sector worldwide is undergoing a major transformation driven by the pressures to reduce the rate of growth in healthcare spending, balance supply and demand, and improve health outcomes [1]. In industrialized countries, factors associated with increased healthcare spending include providing care to a growing aged population with chronic illnesses, incorporating technological advances, overuse and inappropriate use of care technologies, and promoting patient-centered quality of care. In the U.S. one would add the high prices charged for delivering care [2]. Additionally, inequality in access to healthcare is increasing [3].

In an attempt to address the above challenges, many healthcare organizations have adopted transformational performance improvement initiatives such as the Lean management system. Originally developed at Toyota beginning in the 1950's, it has since spread to service industries including healthcare. In healthcare, the definition of Lean and the approach to Lean implementation are highly variable. We define Lean in healthcare as a management philosophy emphasizing patient focus, respect for people, eliminating waste and striving for excellence by engaging staff in continuous improvement and problem solving through a set of practices and tools such as A3 thinking, daily huddles, visual management, $5 \mathrm{~S}$ (sort, set in order, shine, standardize, and sustain), and the PDSA (plan-do-study-act) cycle.

Attention to local context has been recognized as an important factor in Lean healthcare transformation sustainability, and it has been suggested that a uniform approach does not work in all contexts [4, 5]. The attributes of context are, however, often poorly defined, and current knowledge of the role of contextual factors in implementing new practices and methods such as Lean is limited [6]. Our definition of context is broad and includes all regulatory, economic, environmental, and social factors that affect the operational work of a healthcare organization. Furthermore, it is important to recognize that beyond the intra-organizational level, many contextual factors external to the organization may influence the implementation of Lean management in a healthcare organization. We identify four contextual levels: intra-organizational, regional, national, and international.

\section{Intra-organizational level}

The narrowest definition of context includes only intraorganizational factors such as teamwork, change resistance, ability to bridge silos, transparency, leadership commitment, communication, resources, people engagement, and empowerment $[7,8]$. The intra-organizational context is rarely homogenous but rather comprises several sub-contexts in different locations and organizational units.

\section{Regional level}

Regional factors affecting the context around Lean healthcare transformation may include geographical characteristics, market concentration and local economy, interrelations of healthcare organizations, local customs and public expectations, ethnic diversity, local authorities, and regional funding for Lean initiatives. For example, in Canada, several provinces have mandated all health regions to participate in Lean [9], and Ontario has introduced an emergency department (ED) process improvement program based on Lean principles [10].

\section{National level}

The structures of the national healthcare system, the national healthcare funding model, and major stakeholders such as insurance companies play a major role in shaping the national landscape for Lean healthcare transformation. Furthermore, issues related to legislation and policies may influence the flexibility of task reallocation and serve as an inhibitor [11]. Labor unions and tenured staff, especially in the public sector, may hinder employee buy-in [12-15]. Variability in the cultural expectations about the roles of patients and healthcare professionals, acceptable behaviors, and the level of medicalization are other significant influencers.

\section{International level}

There is a fourth contextual level that transcends national borders. Independent of previously described factors such as the national healthcare system model, the healthcare industry around the world has common characteristics that differentiate it from other fields such as manufacturing [16]. One limitation of implementing Lean in healthcare is that it is still relatively new in in this sector, and there is a lack of empirical evidence to convince top management of its benefits [17]. Critical breaches in the assumptions behind Lean such as the definition of the customer and limitations of capacityled design around influencing demand or utilizing freedup resources may emerge in the process of adopting Lean to healthcare [18]. Furthermore, some factors influencing healthcare Lean transformation are similar in all countries. For example, differences in the business logics of private and public healthcare organizations lead to different challenges in implementing Lean. The model of Lean implementation set by other service industries may be better suited to the private healthcare context [19, 20]. A tailored approach to Lean implementation may be necessary in the public sector, as public healthcare institutions are impacted by competing or even contradictory political, regulatory, and commissioning priorities [18]. 
Heavy bureaucracy, rigid policies, and regulations often reduce flexibility and complicate Lean implementation $[13,19]$. Despite these challenges, Lean management has been shown to be feasible in the public hospital settings in many countries across the world [21-29].

\section{Benchmarking and Multi-Level Context}

The underlying assumption of performance benchmarking is that the organizations have shared objectives represented by measurable outcomes. Following Camp, we define benchmarking as "...the search for the best industry practices which will lead to exceptional performance through the implementation of these best practices" [30]. In Lean healthcare, benchmarking could facilitate defining the best implementation strategies and practices to maximize the impact of Lean initiatives in healthcare organizations. Since most Lean healthcare organizations are still in the early stages of their Lean journey [31], benchmarking whole organizations may be neither optimal nor feasible. However, benchmarking individual quality improvement efforts may provide valuable information that helps healthcare organizations gradually reach Lean maturity. The theoretical concepts are widely shared among Lean healthcare organizations, but the practical concepts and applications are highly variable. Most healthcare organizations around the world adhere to one or several quality frameworks and value statements, many of which are compatible with Lean management philosophy. Some of the most widely recognized and adopted quality frameworks in healthcare are the Triple Aim developed by the Institute of Healthcare Improvement [32] and its modification, the Quadruple Aim [33], as well as the domains of healthcare quality defined by the National Academy of Medicine in the United States [34]. In the context of Lean healthcare, the Toyota 4P model [35] and the 10 Shingo Guiding Principles [36] are value statements adopted by many organizations. While the challenges, aims, and quality frameworks in healthcare are international, the context in which healthcare organizations in different countries and areas operate is highly variable, warranting special attention in benchmarking.

There is a call for cross-comparative research to assess possible cultural influences on Lean implementation. In their comprehensive review on Lean in healthcare, D'Andreamatteo and coworkers conclude that there are few cross-comparative and multi-site analyses, and identify the need for more research concerning different countries to allow an appreciation of the extent of using Lean in healthcare and a better evaluation of possible cultural influences [37]. No framework exists to guide such studies, and internationally relevant and applicable outcome domains are yet to be defined. Since healthcare organizations are open systems, understanding the context of Lean implementation beyond the intraorganizational level is important to reach the organization's performance improvement goals. Cross-national comparisons would benefit early adopters and healthcare organizations in smaller countries with limited opportunities for local benchmarking and scarce research evidence directly relevant to their context. Furthermore, a better understanding of contextual differences and similarities between countries would facilitate interpreting international research findings and using them to guide a successful Lean transformation.

In this first attempt to address the challenges of crosscomparative research in Lean healthcare, we identified two equally important dimensions as prerequisites for reliable and meaningful performance benchmarking: clearly defined contextual level and a universally relevant, applicable, and balanced set of domains for benchmarking. We asked three research questions:

- On which of the context levels and outcomes has benchmarking been used in Lean healthcare?

- What outcome domains are applicable and relevant for benchmarking the performance of Lean healthcare organizations operating in different contexts?

- Based on the extent to which different contexts and outcome domains have been used to benchmark Lean initiatives, what should be the agenda for future Lean benchmarking research in healthcare?

We aim to address the first question by conducting a systematic review of current literature on benchmarking Lean in healthcare and identifying the levels of cultural context reported. Uncovering the similarities in widely used healthcare quality frameworks and value statements, we address the second question by developing a conceptual framework with a widely applicable and balanced set of outcome and quality domains and examine the articles identified through the systematic review using this novel framework. Informed by the contextual levels and outcome domains used in the articles identified through the systematic review, we identify major gaps in the existing research and propose a future research agenda that would fill those gaps and provide actionable results to the international Lean healthcare audience. Figure 1 presents the structure of this article.

\section{Methods}

The systematic review was conducted in accordance with the Preferred Reporting Items for Systematic reviews and Meta-analyses (PRISMA) and the associated checklist was used [38]. On October 4, 2019, we 


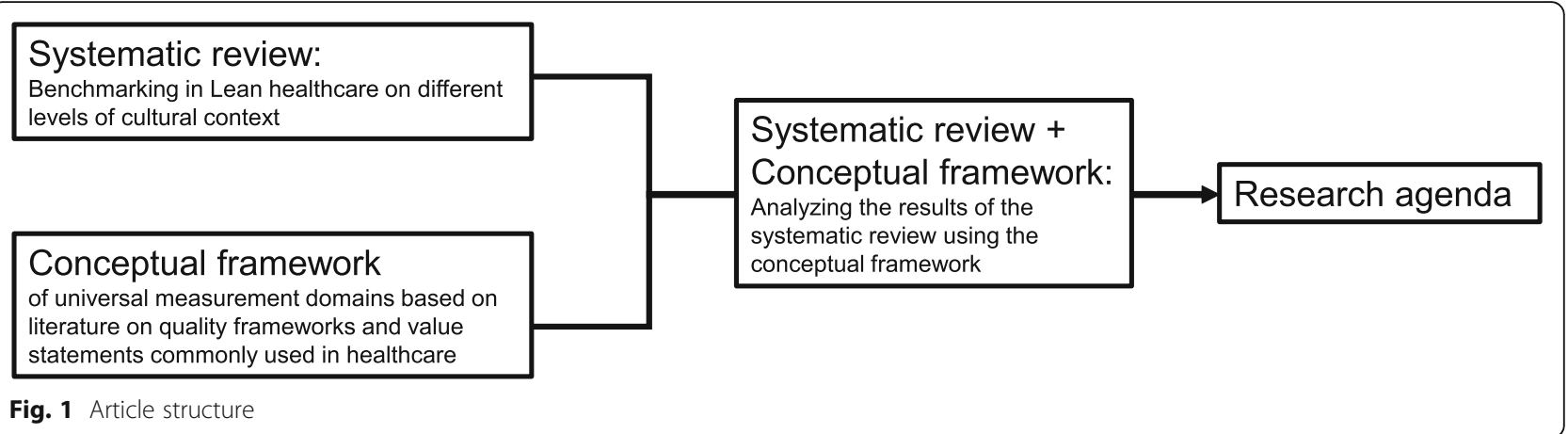

conducted a literature search of English-language articles with unlimited publication years in three databases widely used for literature on healthcare management: Pubmed, Scopus, and Web of Science. The following search strategy was selected to capture all relevant articles reporting benchmarking in Lean healthcare organizations:

(Hospital OR Healthcare OR Health care) AND (Lean OR "Toyota Production System" OR "Robust Process Improvement") AND (benchmarking OR compare OR comparison) NOT (obesity) NOT (adipose).

The terms "obesity" and "adipose" were used for excluding articles using the term "Lean" in the context of nutrition status or weight.

To be considered, the articles had to be published in English, publicly available, and peer reviewed. Furthermore, the articles had to fulfill the following predefined criteria: (1) the study was set in a hospital or healthcare context, (2) compared original data from two or more units or organizations, (3) reported using Lean methods such as those described previously in our definition of Lean, and (4) reported benchmarked outcomes in the context of Lean. The articles identified through the initial search and additional articles from reference lists went through three rounds of review: title screening, abstract review, and full text review. The review was performed by two authors (AJ and ER) independently. All disagreements were resolved through further review and discussion and, if required, with a tie-breaking vote by a third author (JB).

The methodological quality and risk of bias assessment was done at the study level for each included article using the Critical Appraisal Skills Programme (CASP) and the Specialist Unit for Review Evidence (SURE) checklists to ensure a standardized assessment across the studies [39-41]. Both CASP and SURE checklists comprise 11-12 criteria expressed as questions that are rated on a scale of yes/no/can't tell. Examples of the questions include: Did this study address a clearly focused issue? Have the authors taken account of the potential confounding factors in the design and/or in their analysis? Are the measures of exposures and outcomes appropriate? Are the statistical methods well described? The criteria included in the CASP checklists are organized into 3 sections: validity, reporting and accuracy of the results, and generalizability of the results. In the absence of official guidance for categorizing the quality of articles based on the checklists, we defined low quality as articles meeting less than $50 \%$ of the criteria; intermediate quality as meeting $50-74 \%$ of the criteria, and high quality as meeting $75 \%$ or more of the criteria on the checklists. Additionally, the studies were categorized according to the Oxford Center for Evidence-Based Medicine (CEBM) Levels of Evidence [42]. The Cochrane recommended risk of bias assessment tables for systematic reviews are designed for randomized controlled trials and not applicable for assessing other study designs. Quantitative meta-analyses were not performed due to the heterogeneity of the included studies.

Finally, we reviewed the literature to identify commonly used healthcare quality frameworks and value statements, and performed a detailed content analysis of their key elements. We then used a bottom-up approach to reveal shared domains emerging from their principles to develop a conceptual framework, which we used to further explore the articles identified through the systematic review.

\section{Results}

\section{Systematic review}

The initial search yielded a total of 960 articles: 159, 279, and 522 articles in Pubmed, Scopus, and Web of Science respectively. The authors identified an additional 22 articles through article reference lists. After removing 94 duplicates, the remaining 888 articles first went through title screening, and the abstracts of 209 articles were reviewed to determine if they met the predetermined inclusion criteria. A total of 38 articles were selected for full text review, from which 22 articles fulfilling the criteria were identified and thus included in the final review. The two original reviewers (AJ and ER) reached agreement in all cases and no tie-breaking vote 


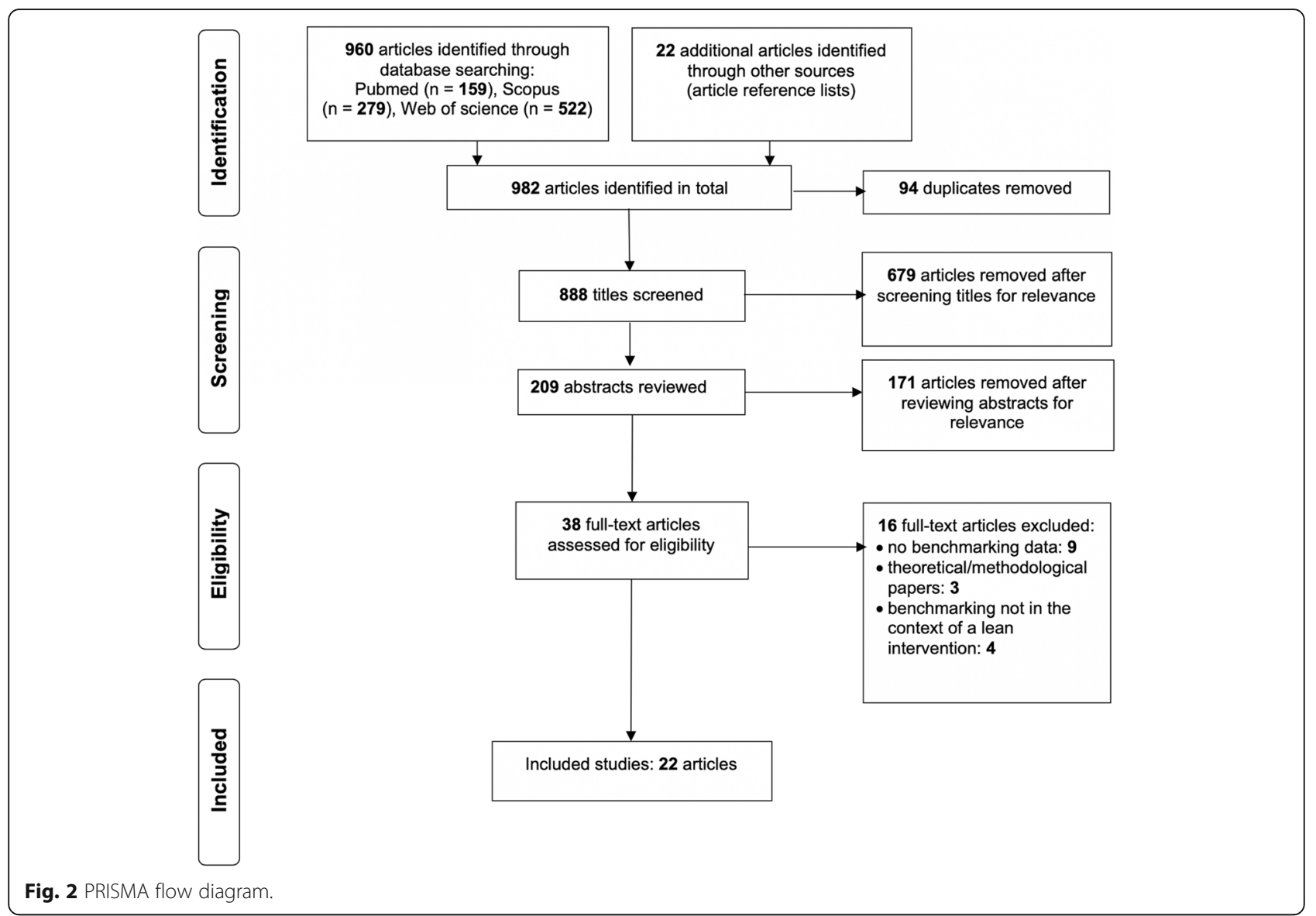

by the third author (JB) was necessary. Figure 2 presents the PRISMA flow diagram for the article selection process.

We assessed the methodological quality and risk of bias in the 22 included articles using the CASP and SURE checklists, categorizing the overall quality of the articles as low (4 articles) [43-46], intermediate (13 articles) [47-59], or high (5 articles) [31, 60-63]. All studies were crosssectional (CEBM 4) [31, 46, 51, 54, 55], controlled interrupted time series (CEBM 3b) [47, 48, 50, 56, 60, 61, 63], or case studies (CEBM 4) [43-45, 49, 52, 53, 57-59, 62] by design. The overall quality and other detailed characteristics of the 22 studies are summarized in Table 1 . The 22 articles originated in 9 different countries: Australia (1) [62], Canada (2) [45, 50], Malaysia (1) [51], The Netherlands (4) [46, 57-59], Saudi-Arabia (2) [43, 44], Spain (1) [52], Sweden (2) [54, 56], the UK (3) [59-61], and the US (9) [31, 47-49, 53, 55, 58, 59, 63], with one article reporting results from Europe without detailed information about the specific country [58]. The publication years ranged from 2008 to 2018. Six studies indicated that targeted resources were utilized in the reported Lean initiative $[45,49,54,55,60,62]$.
We examined the 22 articles using two different categorizations: first, the level of context and second, the reported outcome domains. The most commonly used level of context was national level (10 articles) [31, 46, 51-57, 63]. All studies provided basic information on context and study setting, but there was high variation in the type and detail of contextual factors reported by the studies. A majority of the studies referred to context and culture-related issues in the discussion section, but few included an indepth discussion of the relationship between the elements of organizational culture and the study results $[60,61]$. The most frequent outcome domain in the included articles was service provision, especially process metrics $[31,43,44,46-50,52,53,55,58$, $59,63]$. None of the studies reported outcome measures from all outcome domains in out proposed framework. Notably, regardless of the core principles of Lean described previously, Lean studies reporting outcomes related to patient experience, employed and affiliated staff, costs, and strategic perspective were scarce. The detailed results by category are presented below. 
Table 1 Characteristics of the 22 articles included in the systematic review grouped by the level of context

\begin{tabular}{|c|c|c|c|c|}
\hline $\begin{array}{l}\text { Author } \\
\text { Year }\end{array}$ & $\begin{array}{l}\text { Study type/ } \\
\text { Overall quality }\end{array}$ & $\begin{array}{l}\text { Country/ } \\
\text { region } \\
\text { Department/ }\end{array}$ & Setting for benchmarking & Benchmarking measures \\
\hline
\end{tabular}

Intra-organizational level

Abdelhadi A Multiple case Saudi-Arabia

2015

study/ Low

Abdelhadi A, Multiple case Shakoor M [44] study/ Low 2014

$\begin{array}{ll}\text { New S et al. } & \text { Controlled } \\ {[60]} & \text { interrupted } \\ 2016 & \text { time series/ } \\ & \text { High }\end{array}$

$\begin{array}{ll}\text { Raab SS } & \text { Controlled } \\ \text { et al. [47] } & \begin{array}{l}\text { interrupted } \\ \text { time series/ } \\ \text { Intermediate }\end{array} \\ \text { Robertson E } & \begin{array}{l}\text { Controlled } \\ \text { et al. [61] }\end{array} \\ \begin{array}{l}\text { interrupted } \\ \text { time series/ } \\ \text { High }\end{array}\end{array}$

Venkateswaran Controlled $S$ et al. [48] interrupted

2013 time series/ Intermediate
US/Louisiana Hospital warehouses

$\begin{array}{ll}\text { UK } & \text { Comparing orthopedic trauma } \\ \text { Orthopedic OR } & \begin{array}{l}\text { theater and an elective } \\ \text { orthopedic theatre in the same } \\ \text { trust }\end{array}\end{array}$

US/ Comparing two sister

Pennsylvania histopathology sections in one

Histopathology University Medical Center in laboratory Pittsburgh

UK

Surgery/OR

Comparing a specialist elective orthopedic hospital's plastic surgery team with an orthopedic theater team
-Takt time

(male/female) within the same

comparing inpatient and outpatient pharmacies at one

-Takt time

Primary intervention:

-WHO-checklist compliance

."Glitch count" (intraoperative

process disruptions)

- Oxford NOTECHS II

- Clinical outcomes (90D):

-LOS

-Complications

-Readmissions

Secondary intervention:

-1st operation start time

-Productivity ratio (work units/ FTEs)

-NOTECHS II (non-technical skills) ."Glitch rate" (technical skills)

-WHO checklist compliance

-Patient safety outcomes:

-Complication rate (90D)

-Readmission rate (90D)

-LOS in hospital
Comparing three hospitals' central warehouses in one health system
-Monthly inventory turnovers

-5S audit scores (non-

conformities)
Lean manufacturing principles to identify and eliminate waste and improve workflows

Lean manufacturing principles to identify and eliminate waste and improve workflows $\cdot$-VSM

-Spaghetti diagrams

Primary intervention:

Lean training in

-Muda

-Poka-Yoke

-Flow

-Just-in-time

-Process mapping

-PDCA

-Kaizen

-Philosophy of

continuous participative experimental improvement

-Genchi Genbutsu - Respectful cooperation Secondary intervention: -Improving start time

-PPC system

-A3

-Current state and ideal state identification

A combination of teamwork training and lean process improvement training including:

- Muda

-Poka-Yoke

- Genchi Genbutsu

-Kaizen

-Flow

-Just-in-time

- Respect and teamwork

-Process mapping

-PDCA

-Philosophy of continuous improvement

Traditional 5S (control group):

- Prework (5S team selection and training, baseline data collection and analysis) -Implementation (performance of 5S) - Post-analysis (evaluating outcome of the improvements) Hybrid 5S (intervention group): 
Table 1 Characteristics of the 22 articles included in the systematic review grouped by the level of context (Continued)

\begin{tabular}{llllll}
\hline $\begin{array}{l}\text { Author } \\
\text { Year }\end{array}$ & $\begin{array}{l}\text { Study type/ } \\
\text { Overall quality }\end{array}$ & $\begin{array}{l}\text { Country/ } \\
\text { region } \\
\text { Department/ } \\
\text { specialty }\end{array}$ & Setting for benchmarking & Benchmarking measures & \\
& &
\end{tabular}

\begin{tabular}{ll}
\hline & -Kaizen structure: \\
-Observation and & preparation (identifying \\
problem areas, VSM) & -Planning lean initiatives \\
-Implementation & (performance of first 4 \\
S's + developing an & inventory model) \\
-Measurement of & improved process \\
(evaluating effectiveness, \\
efficiency, relevance, and \\
impact)
\end{tabular}

\section{Regional level}

Culig $\mathrm{MH}$ et al.

[49]

2011

- Intermediate
US

Cardiac surgery

Comparing results of a program

with regional rates from the

Society of Thoracic Surgeons

National Adult Cardiac Surgery

Database leraci $S$ et al.
$[62]$

2008
Case study with regional benchmarks/ High
Australia/New South Wales ED
Kielar AZ et al.[45] 2010

Vermeulen MJ et al. [50] 2014
Case study with regional benchmarks/ Low

\section{Controlled} interrupted time series/ Intermediate
Canada/Ontario Benchmarking the performance Radiology

\section{Canada/Ontario} $\mathrm{ED}$ of radiology units against provincial acceptable wait times defined by Ontario government

Benchmarking EDs in Ontario, Canada
Benchmarking the ED of a single hospital against New South Wales Department of Health mark waiting times

National level

Ahmed $\mathrm{S}$ et al. [51] 2018

Cross-sectional/ Intermediate
Malaysia Whole hospitals
Random sample of 16 hospitals

in peninsular Malaysia; comparisons by respondents' gender, type of hospital and
-Preoperative demographics -Surgery type (off-pump, urgent, emergency, emergency salvage) -Total LOS

-Post procedure LOS

- Use of blood products

-Complications (mortality, any

complications, any infection,

atrial fibrillation, cardiac arrest,

heart block requiring permanent pacemaker, prolonged ventilation $>24 \mathrm{~h}$, pneumonia, renal failure, reoperations, stroke, readmission within 30 days) -|CU stay

-Mean total ventilation

-Compliance with NSW Department of Health benchmark for waiting times in each of the five Australasian Triage Scale (ATS) categories in Fast Track and Standard ED groups.

-Compliance with acceptable wait times for CT/MRI scans (28 days) set by the province

Primary outcomes

- Length of stay

- Median time to physician - Percentage of admitted and nonadmitted patients missing provincial ED LOS targets

Secondary outcomes

- Left without being seen rate

-30-day mortality

-30-day readmission rate among

admitted patients

.72-hour revisit rate among

discharged patients

Six Lean constructs:

-Continuous quality

improvement

-Lean management initiatives
-Vision and values

-VSM

- Defined metrics (balanced scorecard)

-Pull methodology

-Daily huddles

-A3-problem solving - Ongoing mentoring of

frontline staff

-Visual management -Kanban

- Standardization

(standard work)

- One-by-one processing .5S

- Leveling the workload - Root cause analysis

-Physical space reallocation - Creating two distinct patient tracks (lowcomplexity patients "fast track", high-complexity patients "normal track")

-Rapid Improvement Event

A lean improvement approach, specific tools not described

Perceptions of Lean and quality improvement 
Table 1 Characteristics of the 22 articles included in the systematic review grouped by the level of context (Continued)

\begin{tabular}{|c|c|c|c|c|}
\hline $\begin{array}{l}\text { Author } \\
\text { Year }\end{array}$ & $\begin{array}{l}\text { Study type/ } \\
\text { Overall quality }\end{array}$ & $\begin{array}{l}\text { Country/ } \\
\text { region } \\
\text { Department/ } \\
\text { specialty }\end{array}$ & Setting for benchmarking & Benchmarking meas \\
\hline & & & working experience & $\begin{array}{l}\text {-Six Sigma initiatives } \\
\text {-Patient safety } \\
\text {-Teamwork } \\
\text {-Quality performance }\end{array}$ \\
\hline $\begin{array}{l}\text { Allaudeen N } \\
\text { et al. [63] } \\
2017\end{array}$ & $\begin{array}{l}\text { Controlled } \\
\text { interrupted } \\
\text { time series/ } \\
\text { High }\end{array}$ & $\begin{array}{l}\text { US } \\
\text { ED }\end{array}$ & $\begin{array}{l}\text { Benchmarking one VA ED against } \\
\text { other similar VA facilities in the } \\
\text { US }\end{array}$ & $\cdot$ ED LOS \\
\hline
\end{tabular}

Boronat $\mathrm{F}$ et al. Case study with

$\begin{array}{ll}{[52]} & \text { national } \\ 2018 & \text { benchmarks/ } \\ \text { Intermediate }\end{array}$

Spain/Catalonia Urology

Intermediate

Comparing one Urology department with national benchmarks in Catalonia, Spain •Risk-adjusted et al.[53] 2009

Holden RJ et al. [54] 2015

Lee JY et al. [55]
US ED

$\begin{array}{ll}\text { Multiple case } & \text { US } \\ \text { study/ } & \text { ED } \\ \text { Intermediate } & \end{array}$

Cross-sectional/ Sweden Intermediate Whole hospitals

Three hospitals, comparisons by hospital, unit acuity, and professional role

Comparing hospitals using Six

Cross-sectional/ US Intermediate
Comparing four ED departments (2 academic, 2 community)
Whole hospitals
- Global patient LOS

-Percentage of patients that left unseen (2/4 EDs)

-Patient volume

- Patient satisfaction (Press Ganey or Gallup surveys)

-Attitude toward lean -Commitment toward lean -Perceived justice of lean implementation

-Perceived flow improvement due to lean

- Responsiveness capability -Patient safety -Cost in the US

\section{Lean methods} S๑ ${ }^{\circledR}$

-Risk-adjusted length of stay index RALOS by IASIST ${ }^{\circledR}$

that left


Table 1 Characteristics of the 22 articles included in the systematic review grouped by the level of context (Continued)

\begin{tabular}{llllll}
\hline $\begin{array}{l}\text { Author } \\
\text { Year }\end{array}$ & $\begin{array}{l}\text { Study type/ } \\
\text { Overall quality }\end{array}$ & $\begin{array}{l}\text { Country/ } \\
\text { region } \\
\text { Department/ } \\
\text { specialty }\end{array}$ & Setting for benchmarking & Benchmarking measures & \\
& &
\end{tabular}

\begin{tabular}{ll}
\hline & \\
& \\
Poksinska BB & Controlled \\
et al. [56] & interrupted \\
2017 & time series/ \\
& Intermediate
\end{tabular}

Shortell S et al. Cross-sectional/ US

$\begin{array}{lll}{[31]} & \text { High } & \text { Whole hospitals } \\ 2018 & \end{array}$

Sweden

Comparing Lean and non-Lean groups in a national sample of health centers (primary care)

Benchmarking hospitals that reported doing Lean in a national sample of US hospitals according to ownership, membership in a system or network, area type, teaching status, and bed size

Benchmarking one radiotherapy institute against Dutch Society for Radiotherapy and Oncology national norms

benchmarks/ Oncology/
Intermediate radiotherapy

International level

van Lent WAM Case study with The et al. [58] 2009 international benchmarks (baseline only)/ Intermediate
Primary care Netherlands, US, Europe

A Dutch CDU benchmarked with two other CDUs Oncology
-Number of staff involved with

diagnosis

-Pull

-One stop shop for diagnosis

- Non-value adding activities

National Patient Satisfaction

survey $(2009,2011,2013), 5$

subject categories:

-Accessibility and waiting

- Responsiveness

-Patient involvement

-Communication and information

sharing

-General impression

- Self-reported Lean maturity

- Number of years doing Lean

- Number of units doing Lean

- Number of tools reported as

High or Very High

- Overall Lean leadership

commitment index

-Daily management system index

-Education and training scale

- Self-reported performance index

-Percentage of patients exceeding the national norms for waiting times (palliative and curative patients)

Baseline characteristics

- Patient case mix

- Services offered

- Total patient visits in 2004

-Estimated total patient visits in

2005

- Indexed average number of patients treated per bed per month

-Indexed average number of patient visits per month per total CDU staff

-Indexed average number of patient visits per nurse per month

$\begin{array}{lll}\text { Van Vliet EJ } & \text { Multiple case } & \text { UK, US, The } \\ \text { et al. [59] } & \text { study/ } & \text { Netherlands } \\ \text { 2011 } & \text { Intermediate } & \text { Ophthalmology }\end{array}$

Comparing 3 cataract pathways

- Lead time

-Access time

-Waiting time for surgery

- Number of hospital visits

- Costs

- Number of patients receiving

their care in autonomous

cataract work cells

-Average number of physical

patient transfers

- Number of different staff

functions

- Number of one-stop diagnosis,

preassessments, and surgeries

- Number of decoupling points

- Number of patients who did not
-Lean group (23 health centers) : at least 3 years experience working with lean

-Non-lean group: no lean activities (23 health centers)

A 63-item survey addressing the self-reported Engagement in Lean, Lean Six Sigma or RPI -Duration, extent, and maturity of lean implementation

Use of tools and methods

- Lean behaviors

- Performance improvements

$.5 \mathrm{~S}$

-Multidisciplinary team based projects

-PDSA

-Root-cause analysis -VSM

-Elimination of waste - Rapid-Plan Assessment -Reorganization of inventory

-Visual management

- Operational focus

-Autonomous work cell -Physical layout of resources -Multi-skilled team - Pull planning -Elimination of wastes 
Table 1 Characteristics of the 22 articles included in the systematic review grouped by the level of context (Continued)

\begin{tabular}{|c|c|c|c|c|c|}
\hline $\begin{array}{l}\text { Author } \\
\text { Year }\end{array}$ & $\begin{array}{l}\text { Study type/ } \\
\text { Overall quality }\end{array}$ & $\begin{array}{l}\text { Country/ } \\
\text { region } \\
\text { Department/ } \\
\text { specialty }\end{array}$ & Setting for benchmarking & Benchmarking measures & Lean methods \\
\hline & & & & $\begin{array}{l}\text { receive any additional } \\
\text { preassessments } \\
\text {-Number of patients who did not } \\
\text { revisit the hospital for a first } \\
\text { review by an ophthalmologist } \\
\text { - Number of average coordination } \\
\text { actions per patient }\end{array}$ & \\
\hline
\end{tabular}

Abbreviations: CDU Chemotherapy Day Unit; ED Emergency Department; LOS Length of Stay; OR Operating Room; PDCA Plan-Do-Check-Act; PDSA Plan-Do-StudyAct; PPC Perfect Patient Care; RPI Robust Process Improvement; VA Department of Veterans' Affairs; VSM Value Stream Mapping

\section{On which of the context levels has benchmarking been used in healthcare? \\ Intra-organizational benchmarking}

We identified six studies that reported benchmarking in the context of Lean management on the intraorganizational level (Table 1) [43, 44, 47, 48, 60, 61]. Three articles benchmarked among sites that had implemented different Lean initiatives [43, 44, 48]. Three other articles benchmarked the outcomes of a Lean intervention site with non-Lean control sites [47, 60, 61], with improved process outcomes in the Lean intervention sites reported in all three articles but no significant differences in patient outcomes between the Lean intervention and control sites in two articles $[60,61]$.

The description of contextual factors varied across the studies. All six studies provided the geographical location (country and/or region) and general organizational setting of the study [43, 44, 47, 48, 60, 61]. However, there was little consistency in reporting other contextual factors across the six studies. While the information could be indirectly deduced from the location and hospital type, only two studies included explicit descriptions of hospital funding and governance models [43, 44]. One study included a detailed description of the national healthcare system [44]. Hospital teaching status was disclosed in two studies [44, 60]. The intervention in one study included Crew Resource Management aimed at improving teamwork and communication [61], and culture-related elements, i.e. non-technical skills, were included in the intervention and outcome measures of two studies [60, 61]. In the discussion section, three studies mentioned organizational culture and its potential influence on the results: one mentioned Lean education and development of continuous improvement culture [43]; one discussed the effect of culture on study methodology [47]; and one discussed the influence of a natural disaster, variations in operational volume, and employee cooperation and adaptability [48]. Two studies provided an in depth discussion of the relationship between elements of organizational culture and the study results $[60,61]$.

\section{Regional benchmarking}

A total of four studies reported regional-level benchmarking in Lean healthcare (Table 1) [45, 49, 50, 62]. Three of the studies reported improved outcomes after Lean implementation $[45,49,62]$ whereas one study found initial benefits that seemed to diminish or disappear when benchmarked with results from control sites [50].

All four studies provided details on the location and, to a variable degree, the organizational characteristics of the study sites $[45,49,50,62]$. and one provided an overview of the national healthcare system [45]. Two studies included elements in their intervention aimed at facilitating cultural change $[49,50]$. One study discussed the mechanisms and role of culture change, including a "no blame" culture and empowerment of staff [49]. whereas another identified the lack of measuring contextual factors such as management involvement and staff buy-in as a limitation.[50] Two studies did not discuss the role of contextual factors.[45, 62].

\section{National benchmarking}

Ten studies used benchmarking in Lean healthcare on a national level (Table 1) [31, 46, 51-57, 63]. Two studies found Lean implementation improved performance against national benchmarks $[52,57]$, and another three studies reported improved outcomes after the implementation of Lean initiatives [53, 55, 63].

All ten studies defined the location [51-54,63] and, with the exception of one study [46], all provided some organizational characteristics of study sites, albeit with a varying degree of detail. Five studies reported the teaching status or academic affiliation, or the lack thereof, of study sites [31, 53-55, 63], and the ownership (public or private) was explicitly stated in five studies [31, 51, 52, $54,55]$. With the exception of the study utilizing patient satisfaction survey data [56], all survey-based studies included some questions related to organizational culture $[31,51,54,55]$. Two studies included elements targeting staff buy-in and cultural change in the intervention [52, 57]. Measures related to organizational culture, i.e. safety 
culture, employee satisfaction, and absenteeism, were used as outcomes in one study [57].

All ten studies referred to culture-related and contextual issues in the discussion. Five studies identified the general associations of organizational culture and context with outcomes $[31,51,55,57,63]$. Specific cultural context elements identified as important contributing factors were team training and feedback improvement [52], the importance of adapting the Lean approach to local culture, [53] and the influence of culture and context such as leadership support on outcomes [53]. Two studies acknowledged that the partial knowledge of context factors was a limitation of the study $[46,56]$. One study outlined three levels of context: unit/role/team, regional/hospital, and national level [54], but issues beyond the organizational culture, particularly the influence of the local national healthcare system were discussed in only one study [52].

\section{International benchmarking}

Only two studies reported benchmarking in Lean healthcare on the international level (Table 1) [58, 59]. One used benchmarking to compare performance levels and operational differences in three organizations with the results guiding the design of a Lean process improvement intervention in one of the organizations, but provided little contextual information besides the geographical location about the benchmarking sites nor discussion of the role and impact of contextual factors [58].

The other study benchmarked the operations of three Lean eye hospitals in the UK, the US and the Netherlands, addressing six Lean aspects [59]. The authors concluded that the operational focus of the participating hospitals was influenced by external contextual factors leading to different objectives. This study provided details on the location, type, teaching status, and operational volume of the organizations. In the discussion, the authors identified the effect of environmental context on how Lean was applied and the role of organizational culture in Lean implementation. Furthermore, the authors identified the study methodology as a limiting factor for the assessment of the effects of contextual factors.

\section{What outcome domains have been used within each context level? \\ Conceptual framework for the selection of outcome and quality measures to facilitate benchmarking}

The above review revealed a wide variation and a lack of consistency in the selection of outcome measures among the benchmarking studies. To address this issue, we integrated the overarching themes of 10 quality frameworks [32] and four value statements $[35,36,71,72]$ into a single framework with four main domains: patients, employed and affiliated staff, costs, and service provision. The main domain of patients comprises two subdomains: clinical outcome and experience. The service provision domain includes four subdomains: access, processes, continuous improvement, and strategic perspective. Table 2 shows the relevance of these key domains regardless of the framework or value statement chosen by an individual healthcare organization highlighting the applicability of these domains in Lean healthcare organizations despite the variability in the definition of and approach to Lean.

We classified the 22 articles identified through the systematic review according to the benchmarked outcomes using the proposed conceptual framework and the four levels of context identified through the literature (Table 3). Unsurprisingly, the most frequent main domain among the 22 articles was service provision, which was a focus in 17 articles [31, 43-50, 52, 53, 55, 57-59, $62,63]$. Of these 17 articles, 14 used outcome measures related to processes $[31,43,44,46-50,52,53,55,58,59$, 63], and five articles used outcome measures related to access to care $[45,50,57,59,62]$. Clinical outcomes were benchmarked in seven articles $[31,49,50,52,55$, $60,61]$, and patient experience in two articles.[53, 56] Factors related to employed and affiliated staff were benchmarked in three $[31,51,54]$ and costs in two articles [55, 59]. Only one article [31] benchmarked outcomes related to continuous improvement or strategic perspective, both subdomains under the main outcome domain of service provision.

\section{Patients: clinical outcome}

In the critical appraisal, four of the seven articles that benchmarked clinical outcomes were categorized as intermediate $[49,50,52,55]$ and three as high overall quality [31, 60, 61]. Two articles represented benchmarking on intra-organizational, $[60,61]$ two on regional, $[49,50]$ and three on national level of context $[31,52,55]$. Three studies indicated a positive effect of Lean implementation on patient outcomes, [49, 52, 55] whereas three studies failed to demonstrate a positive effect $[50,60,61]$. One study used a self-reported performance index that included, among other metrics, measures related to patient outcomes such as reducing medical errors [31].

\section{Patients: experience}

The two studies that benchmarked patient experience were both categorized as intermediate overall quality and represented the national level of context [53, 56]. However, their results were contradictory: some Lean 


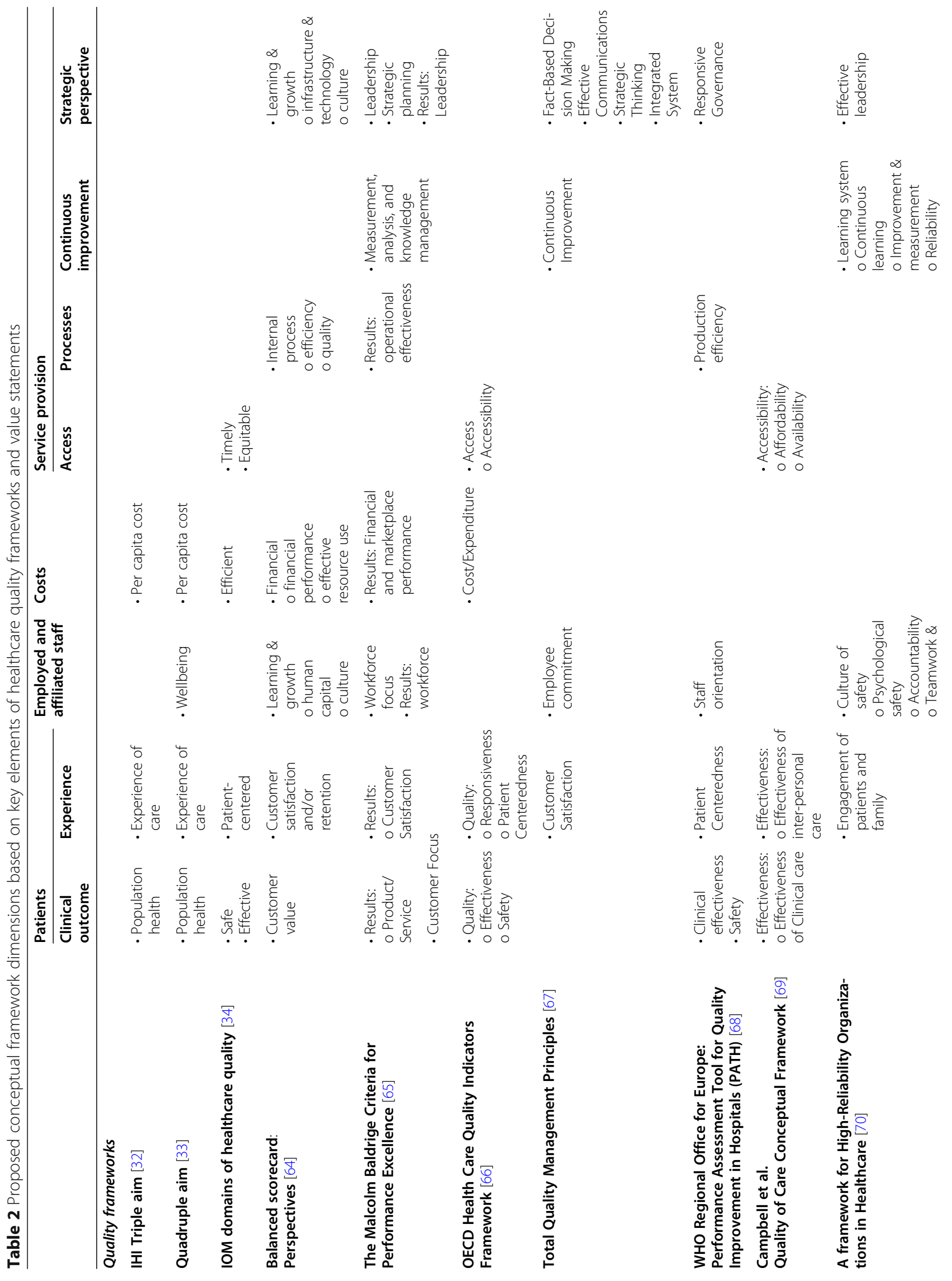




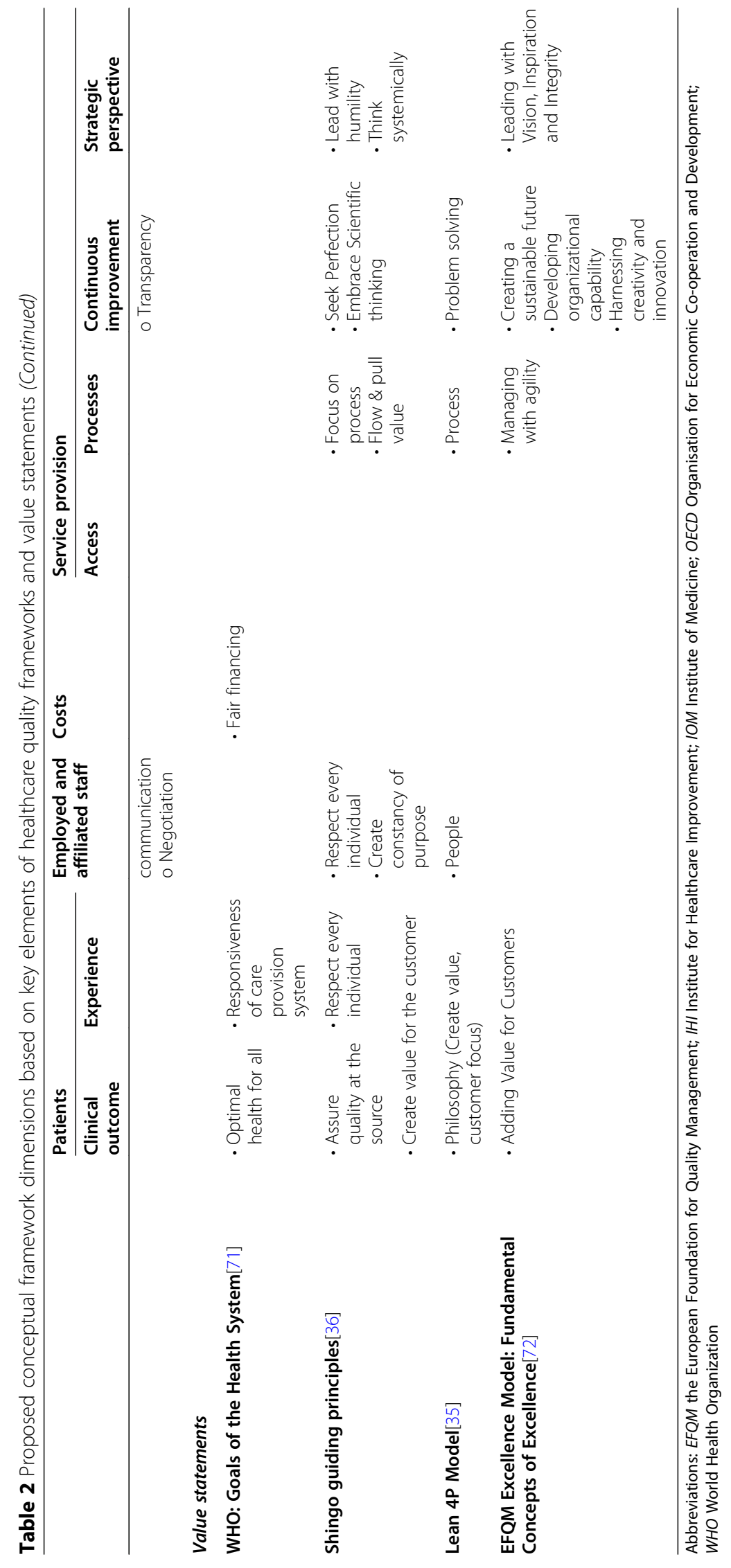


Table 3 Classification of the articles included in the systematic review using the proposed conceptual framework

\begin{tabular}{|c|c|c|c|c|c|c|c|c|c|}
\hline \multirow[t]{2}{*}{ Context level } & \multirow[t]{2}{*}{ Article } & \multicolumn{2}{|l|}{ Patients } & \multirow{2}{*}{$\begin{array}{l}\text { Employed and } \\
\text { affiliated staff }\end{array}$} & \multirow[t]{2}{*}{ Costs } & \multicolumn{4}{|c|}{ Service provision } \\
\hline & & $\begin{array}{l}\text { Clinical } \\
\text { outcome }\end{array}$ & Experience & & & Access & Processes & $\begin{array}{l}\text { Continuous } \\
\text { improvement }\end{array}$ & $\begin{array}{l}\text { Strategic } \\
\text { perspective }\end{array}$ \\
\hline \multirow{6}{*}{$\begin{array}{l}\text { Intra- } \\
\text { organizational }\end{array}$} & Abdelhadi A[43] & & & & & & $x$ & & \\
\hline & $\begin{array}{l}\text { Abdelhadi A, } \\
\text { Shakoor M[44] }\end{array}$ & & & & & & $x$ & & \\
\hline & New $S$ et al .[60] & $x$ & & & & & & & \\
\hline & Raab SS et al .[47] & & & & & & $x$ & & \\
\hline & $\begin{array}{l}\text { Robertson E et al } \\
\text { [61] }\end{array}$ & $x$ & & & & & & & \\
\hline & $\begin{array}{l}\text { Venkateswaran S } \\
\text { et al .[48] }\end{array}$ & & & & & & $x$ & & \\
\hline \multirow[t]{4}{*}{ Regional } & $\begin{array}{l}\text { Culig MH et al } \\
\text { [49] }\end{array}$ & $x$ & & & & & $x$ & & \\
\hline & leraci S et al. .62] & & & & & $x$ & & & \\
\hline & Kielar AZ et al .[45] & & & & & $x$ & & & \\
\hline & $\begin{array}{l}\text { Vermeulen MJ } \\
\text { et al .[50] }\end{array}$ & $\mathrm{X}$ & & & & $x$ & $\mathrm{x}$ & & \\
\hline \multirow[t]{10}{*}{ National } & $\begin{array}{l}\text { Ahmed S et al } \\
\text { [51] }\end{array}$ & & & $\mathrm{x}$ & & & & & \\
\hline & $\begin{array}{l}\text { Allaudeen } \mathrm{N} \text { et al } \\
\text {.[63] }\end{array}$ & & & & & & $x$ & & \\
\hline & $\begin{array}{l}\text { Boronat F et al } \\
.[52]\end{array}$ & $x$ & & & & & $x$ & & \\
\hline & $\begin{array}{l}\text { Dickson EW et al } \\
\text {.[53] }\end{array}$ & & $x$ & & & & $x$ & & \\
\hline & $\begin{array}{l}\text { Holden RJ et al } \\
\text { [54] }\end{array}$ & & & $\mathrm{X}$ & & & & & \\
\hline & Lee JY et al .[55] & $x$ & & & $x$ & & $\mathrm{x}$ & & \\
\hline & $\begin{array}{l}\text { Pluimers DJ et al } \\
\text { [46] }\end{array}$ & & & & & & $x$ & & \\
\hline & $\begin{array}{l}\text { Poksinska BB et al } \\
\text {.556] }\end{array}$ & & $\mathrm{X}$ & & & & & & \\
\hline & Shortell et al .[31] & $\mathrm{x}$ & & $x$ & & & $\mathrm{x}$ & $x$ & $\mathrm{x}$ \\
\hline & $\begin{array}{l}\text { Simons P et al } \\
\text { [57] }\end{array}$ & & & & & $x$ & & & \\
\hline \multirow[t]{2}{*}{ International } & $\begin{array}{l}\text { van Lent WAM } \\
\text { et al.[58] }\end{array}$ & & & & & & $\mathrm{X}$ & & \\
\hline & $\begin{array}{l}\text { Van Vliet EJ et al } \\
\text {.559] }\end{array}$ & & & & $\mathrm{x}$ & $x$ & $x$ & & \\
\hline
\end{tabular}

initiatives were associated with improved patient satisfaction whereas others were not.

\section{Employed and affiliated staff}

Two studies using the employee perspectives on Lean for benchmarking were categorized as intermediate [51, 54] and one as high overall quality [31]. All three represented the national level of context. None of the studies used non-Lean controls: the studies benchmarked employees' views or education and training on Lean in different types of institutions and roles.

\section{Costs}

One study benchmarked the costs on the national level of context [55] and one study on the international level of context [59]. Both were categorized as intermediate overall quality. Both studies indicated a possible costsaving effect with Lean implementation.

\section{Service provision: access}

Of the five studies benchmarking access, one was categorized as low [45], three as intermediate [50, 57, 59], and one as high overall quality [62]. Three articles benchmarked access on the regional level, $[45,50,62]$ 
one on the national level [57], and one on the international level of context [59]. Three of the five studies indicated that Lean implementation positively affected access $[45,57,62]$, whereas the fourth concluded no significant difference compared to control sites [50], and the fifth study did not have a non-Lean comparison [59].

\section{Service provision: processes}

There were a total of 14 articles that benchmarked process measures. Nine were categorized as intermediate [47-50, $52,53,55,58,59]$, three as low $[43,44,46]$, and two as high overall quality $[31,63]$. Four studies benchmarked processes on the intra-organizational level $[43,44,47,48]$, two on the regional level $[49,50]$, six on the national level $[31,46,52,53,55,63]$, and two on the international level of context $[58,59]$. A majority of the study designs did not include a non-Lean comparison [31, 43, 44, 46, 48, 53, 58, 59]. Five studies reported that Lean implementation had predominantly positive effects on process metrics,[47, 49, $52,55,63]$ whereas in one study a difference-indifferences analyses indicated no benefit for the Lean sites when compared to non-Lean control sites [50].

\section{Service provision: continuous improvement and strategic perspective}

Only one study used benchmarking measures related to continuous improvement represented by the daily management system index, and strategic perspective represented by the Lean leadership commitment index, both subdomains of service provision.[31] The overall quality of this article was high, but it did not use non-Lean controls for benchmarking.

\section{DISCUSSION}

Lean is a set of organizational principles, practices, and problem-solving tools designed for improving quality and processes. The existing literature on benchmarking in Lean healthcare is surprisingly scarce considering the relatively widespread adoption of Lean in healthcare organizations, and is dominated by results from the US much like Lean-related literature in healthcare in general [17]. Furthermore, there is need for improved quality of the research in the area: after critical appraisal, only $22.7 \%$ of the studies were categorized as high overall quality. These findings are consistent with previous systematic reviews that have criticized existing literature on Lean healthcare for the lack of rigorous methodology $[73,74]$. Since Lean has gained popularity in healthcare during the last 15-20 years, the research in this field is still young: all studies included in our systematic review are published in or after 2008. Unsurprisingly, a majority of the included studies focused on benchmarking process metrics, perhaps reflecting the manufacturing origins of Lean tools and methods [75]. Perhaps due to the heterogeneity and relatively low number of articles included in this systematic review, we could not identify any trends in the sustainability of Lean strategies and initiatives over the 10-year period during which the articles were published. Furthermore, benchmarking in Lean healthcare has yet to truly transcend international borders. While many general elements such as patient focus are widely adopted by healthcare organizations implementing Lean, the lack of consensus on the definition of Lean and the highly variable approaches different organizations have taken on their Lean journey may further complicate comparative research in the field.

The context is an important factor to consider in healthcare Lean transformation. Each healthcare organization is inevitably influenced by factors on all four levels of context, and these factors should be recognized and addressed when benchmarking is used; the greater the geographic distance between the benchmarked organizations, the more complex the differences in the context. Identifying the levels of context facilitates a comprehensive approach to help with better understanding the validity of the benchmarking results.

No consensus on the dimensions of performance measurement and benchmarking in Lean healthcare exists. Our proposed conceptual framework identifies the outcome domains based on the values and quality frameworks shared by most healthcare organizations to guide measuring performance and quality in Lean healthcare and facilitate benchmarking. Additionally, the framework could facilitate establishing a balanced set of benchmarking measures reflecting all outcome domains for each level of context.

For leaders and managers our findings suggest that there is some benchmarking research that identifies contextual factors affecting Lean performance that they can use in making decisions about Lean adoption and implementation. But that research is generally limited both in terms of the levels of context addressed in any given study and the types of performance outcomes for which any context is reported. Hence, caution and in-house assessments of contextual factors and their possible effects on Lean will be important.

For researchers, our findings reveal gaps in current research that should be addressed in future studies to increase the likelihood that decisions about Lean adoption and implementation will be better informed with evidence about the potential effects of context. Based on our findings, we suggest the following directions for a future research agenda:

\section{(a) Research on international level benchmarking in Lean healthcare.}

Categorizing the included articles by the level of context indicates that despite the growing interest in 
transformational performance improvement among nearly all countries, benchmarking has rarely been used beyond the national level. Only two of the studies reported international benchmarking, both in distinct clinical subspecialties. The worldwide use of Lean methodology to transform healthcare highlights the need to address the complexities of international benchmarking to expand knowledge in the field.

(b) Essential factors on different levels of context influencing the results of Lean initiatives.

The characteristics of the context reported in existing studies are highly variable and the influence of contextual factors beyond the intra-organizational level was discussed in only one study. Less than one third of the included articles indicated additional resources allocated to the Lean initiative, yet their potential impact on the results was not discussed in depth. Thus, further work is necessary to identify the most essential characteristics of context to enhance the generalizability and applicability of benchmarking results to other countries, regions, and organizations.

\section{(c) Patient-centered benchmarking in Lean healthcare.}

The previously recognized need to tie Lean process improvement efforts to the ultimate goals of healthcare [8] is also evident in our results: patient outcomes were the second most frequent performance domain benchmarked in the studies included in our systematic review. Patient experience, however, was only measured in two studies both on the national level of context indicating an important future direction for patient-centered benchmarking on multiple contextual levels.

\section{(d) System level research using a balanced set of outcome and quality measures.}

The large number of studies using benchmarking measures primarily reflecting processes compared to studies using benchmarking measures reflecting access may also be an indicator of the low maturity of Lean implementation in the healthcare sector. The focus is still primarily on production and intra-organizational processes whereas fewer studies have taken a broader perspective on service provision at the system level beyond the scope of a single organization. Time is the single most frequently used measure for benchmarking in Lean healthcare. Time, while easy to measure and an indicator of patient flow and throughput, cannot adequately measure costs or the quality of care. For a more balanced approach, some of the studies used additional measures such as readmission rates. Most of the studies reported benchmarking measures from only one or two outcome domains. None of the studies used measures from all four main domains and, in particular, studies on benchmarking the subdomains of continuous improvement or strategic perspective are rare, highlighting the need for future studies with a balanced set of benchmarking measures.

\section{Strengths and limitations}

Our systematic review has two main strengths. First, it is based on relatively broad literature search criteria to increase the likelihood of capturing relevant articles. Second, our pre-defined inclusion criteria intentionally allowed a range of study designs, providing as comprehensive an understanding of the existing literature as possible. Furthermore, we conducted a critical appraisal of all included studies and indicate the results in the review text and tables, but did not exclude any articles from the review even if the overall quality was categorized as low.

This systematic review also has limitations. Despite the broad search criteria, we may have missed some articles that used some other terms for benchmarking. To decrease the likelihood, we added the words "compare" and "comparison" to the search strategy. We also cannot discount publication bias, which may have influenced the results of our systematic review. Due to the broad search and inclusion criteria the study designs and outcomes were highly variable. Together with the low overall number of studies, this prevented a meta-analysis of the results.

\section{Conclusions}

Lean empowers frontline staff to eliminate waste and to continuously improve through standard work and problem solving. Studies on benchmarking in Lean healthcare are scarce and mostly limited to intraorganizational, regional, and national levels of context. The most commonly used benchmarking measures represent the domain of service provision, particularly process outcome metrics, and studies with fully balanced sets of benchmarking measures are lacking. Leaders and managers should pay careful attention to the limited extent of information on contextual factors when making evidence-informed decisions based on current Lean healthcare benchmarking literature. The proposed conceptual framework defining the outcome domains emerging from widely used quality frameworks and value statements may facilitate performance benchmarking and spreading best practices in Lean healthcare. Future research in Lean healthcare benchmarking should include international benchmarking, defining essential factors influencing Lean initiatives on different levels of context, patient-centered benchmarking, and systemlevel benchmarking with a balanced set of outcomes and quality measures. 


\section{List of Abbreviations}

CASP: Critical Appraisal Skills Programme; CDU: Chemotherapy Day Unit; CEBM: Center for Evidence-Based Medicine; ED: Emergency department; EFQM: the European Foundation for Quality Management; IHI: Institute for Healthcare Improvement; IOM: Insititute of Medicine; LOS: Length of Stay; OECD: Organization for Economic Co-operation and Development; OR: Operating Room; PDCA: Plan-do-check-act; PDSA: Plan-do-study-act; PPC: Perfect Patient Care; PRISMA: Preferred Reporting Items for Systematic Reviews and Meta-analyses; RPI: Robust Process Improvement; SURE: Specialist Unit for Review Evidence; VA: Department of Veterans' Affairs; VSM: Value Stream Mapping; WHO: World Health Organization; 5S: Lean tool, short for "sort, set in order, shine, standardize, and sustain"

\section{Acknowledgements}

Not applicable.

\section{Authors' contributions}

ER: Conceptualization, Data curation, Formal analysis, Funding acquisition, Methodology, Project administration, Visualization, Writing -original draft; TR: Conceptualization, Resources, Methodology, Writing -review \& editing, SS: Conceptualization, Resources, Methodology, Writing -review \& editing, JB: Conceptualization, Methodology, Writing -review \& editing, AJ: Data curation, Writing -review \& editing, MM: Conceptualization, Resources, Writing -review \& editing, RJ: Conceptualization, Writing -review \& editing, PT: Conceptualization, Methodology, Supervision, Writing -review \& editing. All authors read and approved the final manuscript.

\section{Funding}

The work of ER was supported by personal grants from Foundation for Economic Education, Finland; Finnish Medical Association, Finland; Finnish Society of Anaesthesiologists, Finland; and Pulsus Foundation, Finland. The funders had no role in study design, data collection and analysis, decision to publish, or preparation of the manuscript.

\section{Availability of data and materials}

All data used in the systematic review were obtained from publicly available internet databases (Pubmed, Scopus, and Web of Science). The datasets used during the current study are available from the corresponding author on reasonable request.

\section{Ethics approval and consent to participate}

Not applicable.

\section{Consent for publication}

Not applicable.

\section{Competing interests}

The authors declare that they have no competing interests.

\section{Author details}

${ }^{1}$ Center for Lean Engagement and Research in Healthcare, School of Public Health, University of California, Berkeley, California, USA. ${ }^{2}$ HUS Helsinki University Hospital, P.O.Box 760, 00029 Helsinki, Finland. ${ }^{3}$ Department of Public Health, University of Helsinki, Helsinki, Finland.

\section{Received: 29 October 2020 Accepted: 8 February 2021}

Published online: 19 February 2021

\section{References}

1. Chassin MR, Loeb JM. High-Reliability Health Care: Getting There from Here. Milbank Q. 2013;91(3):459-90.

2. Dieleman JL, Squires E, Bui AL, Campbell M, Chapin A, Hamavid H, Horst C, Li Z, Matyasz T, Reynolds A, et al. Factors Associated With Increases in US Health Care Spending, 1996-2013. JAMA. 2017;318(17):1668-78.

3. Hero JO, Zaslavsky AM, Blendon RJ. The United States Leads Other Nations In Differences By Income In Perceptions Of Health And Health Care. Health Aff (Millwood). 2017;36(6):1032-40.

4. Poksinska B. The current state of lean implementation in health care: literature review. Qual Manag Health Care. 2010;19(4):319-29.

5. Chassin MR. Improving the quality of health care: what's taking so long? Health Aff (Millwood). 2013;32(10):1761-5.
6. Rangachari P. Innovation Implementation in the Context of Hospital QI: Lessons Learned and Strategies for Success. Innov Entrep Health. 2018; 5:1-14.

7. Aij KH, Simons FE, Widdershoven GA, Visse M. Experiences of leaders in the implementation of Lean in a teaching hospital-barriers and facilitators in clinical practices: a qualitative study. BMJ Open. 2013;3(10):e003605.

8. Harrison Ml, Paez K, Carman KL, Stephens J, Smeeding L, Devers K, Garfinkel S. Effects of organizational context on Lean implementation in five hospital systems. Health Care Manag Rev. 2016;41(2):127-44.

9. MacKenzie J, Hall W: Current State of Lean in Canadian Health Care Ottawa: The Conference Board of Canada; 2014.

10. Rotteau L, Webster F, Salkeld E, Hellings C, Guttmann A, Vermeulen MJ, Bell RS, Zwarenstein M, Rowe BH, Nigam A, et al. Ontario's emergency department process improvement program: the experience of implementation. Acad Emerg Med. 2015;22(6):720-9.

11. Mazzocato P, Holden RJ, Brommels M, Aronsson H, Backman U, Elg M, Thor J. How does lean work in emergency care? A case study of a lean-inspired intervention at the Astrid Lindgren Children's hospital, Stockholm, Sweden. BMC Health Serv Res. 2012:12:28.

12. Escuder M, Tanco M, Santoro A. Major barriers in Lean health care: an exploratory study in Uruguay. International Journal of Lean Six Sigma. 2018; 9(4):466-81.

13. Leite H, Bateman N, Radnor Z. Beyond the ostensible: an exploration of barriers to lean implementation and sustainability in healthcare. Production Planning Control. 2019;31(1):1-18.

14. Radnor Z, Boaden R. Lean in Public Services -Panacea or Paradox. Public Money Management. 2008;38(1):3-7.

15. Cerfolio RJ, Ferrari-Light D, Ren-Fielding C, Fielding G, Perry N, Rabinovich A, Saraceni M, Fitzpatrick M, Jain S, Pachter HL. Improving Operating Room Turnover Time in a New York City Academic Hospital via Lean. Ann Thorac Surg. 2019;107(4):1011-6.

16. Stanton P, Gough R, Ballardie R, Bartram T, Bamber GJ, Sohal A. Implementing lean management/Six Sigma in hospitals: beyond empowerment or work intensification? The International Journal of Human Resource Management. 2014;25(21):2926-40.

17. Antony J, Sunder MV, Sreedharan R, Chakraborty A, Gunasekaran A. A systematic review of Lean in healthcare: a global prospective. Int I Qual Reliab Manag. 2019;36(8):1370-91.

18. Radnor ZJ, Holweg M, Waring J. Lean in healthcare: the unfilled promise? Soc Sci Med. 2012;74(3):364-71.

19. Chiarini A, Bracci E. Implementing Lean Six Sigma in healthcare: issues from Italy. Public Money Management. 2013;33(5):361-8.

20. Radnor Z, Osborne SP. Lean: A failed theory for public services? Public Management Review. 2013;15(2):265-87.

21. Chiarini A, Baccarani C. TQM and lean strategy deployment in Italian hospitals. Leadersh Health Serv (Bradf Engl). 2016;29(4):377-91.

22. Rees GH. Organisational readiness and Lean Thinking implementation: findings from three emergency department case studies in New Zealand. Health Serv Manage Res. 2014;27(1-2):1-9.

23. Antony J, Forthun SC, Trakulsunti Y, Farrington T, McFarlane J, Brennan A, Dempsey M. An exploratory study into the use of Lean Six Sigma to reduce medication errors in the Norwegian public healthcare context. Leadersh Health Serv (Bradf Engl). 2019;32(4):509-24.

24. Jorma T, Tiirinki H, Bloigu R, Turkki L. LEAN thinking in Finnish healthcare. Leadersh Health Serv (Bradf Engl). 2016;29(1):9-36.

25. Holden RJ. Lean Thinking in emergency departments: a critical review. Ann Emerg Med. 2011;57(3):265-78.

26. White M, Wells JS, Butterworth $\mathrm{T}$. The impact of a large-scale quality improvement programme on work engagement: preliminary results from a national cross-sectional-survey of the 'Productive Ward'. Int J Nurs Stud. 2014:51(12):1634-43.

27. Antony J, Rodgers B, Cudney EA. Lean Six Sigma for public sector organizations: is it a myth or reality? International Journal of Quality Reliability Management. 2017;34(9):1402-11.

28. Burgess N, Radnor Z. Evaluating Lean in healthcare. Int J Health Care Qual Assur. 2013;26(3):220-35.

29. Ninan D, Zhu J, Kore A, Wasson E, Fullerton T, Ninan B. The Role of Organizational Culture in Operating Room Turnaround Time. Cureus. 2017; 9(5):e1257.

30. Camp RC. Benchmarking: The Search for Industry Best Practices that Lead to Superior Performance. Milwaukee: ASQC Quality Press; 1989. 
31. Shortell SM, Blodgett JC, Rundall TG, Kralovec P. Use of Lean and Related Transformational Performance Improvement Systems in Hospitals in the United States: Results From a National Survey. Jt Comm J Qual Patient Saf. 2018;44(10):574-82.

32. 32. Berwick DM, Nolan TW, Whittington J. The triple aim: care, health, and cost. Health Aff (Millwood) 2008, 27(3):759-69.

33. Bodenheimer $T$, Sinsky C. From triple to quadruple aim: care of the patient requires care of the provider. Ann Fam Med. 2014;12(6):573-6.

34. Institute of Medicine. Crossing the Quality Chasm: A New Health System for the 21st Century. Washington, DC: The National Academies Press; 2001.

35. Liker J. The Toyota Way. 14 management principles from the world's greatest manufacturer. New York: McGraw-Hill; 2004.

36. Shingo Institute. The Shingo Model: Shingo Guiding Principles. https:// shingo.org/model/. Accessed 15 Jan 2020.

37. D'Andreamatteo A, lanni L, Lega F, Sargiacomo M. Lean in healthcare: A comprehensive review. Health Policy. 2015;119(9):1197-209.

38. Moher D, Liberati A, Tetzlaff J, Altman DG, Group P. Preferred reporting items for systematic reviews and meta-analyses: the PRISMA statement. BMJ. 2009;339:b2535.

39. Critical Appraisal Skills Programme 2018. CASP Case Control Study Checklist. https://casp-uk.net/wp-content/uploads/2018/03/CASP-CaseControl-Study-Checklist-2018_fillable_form.pdf. Accessed 13 Jan 2020.

40. Specialist Unit for Review Evidence (SURE). 2018: Questions to assist with the critical appraisal of case-control studies. http://www.cardiff.ac.uk/insrv/ libraries/sure/checklists.html. Accessed 13 Jan 2020.

41. Critical Appraisal Skills Programme. 2018: CASP Cohort Study Checklist. https://casp-uk.net/wp-content/uploads/2018/03/CASP-Cohort-StudyChecklist-2018_fillable_form.pdf. Accessed 13 Jan 2020.

42. Oxford Centre for Evidence-Based Medicine: Levels of Evidence (March 2009). https://www.cebm.net/2009/06/oxford-centre-evidence-basedmedicine-levels-evidence-march-2009/. Accessed 15 Feb 2020.

43. Abdelhadi A. Investigating emergency room service quality using lean manufacturing. Int J Health Care Qual Assur. 2015;28(5):510-9.

44. Abdelhadi A, Shakoor M. Studying the efficiency of inpatient and outpatient pharmacies using lean manufacturing. Leadersh Health Serv (Bradf Engl). 2014;27(3):255-67.

45. Kielar AZ, El-Maraghi RH, Schweitzer ME. Improving Equitable Access to Imaging Under Universal-Access Medicine: The Ontario Wait Time Information Program and Its Impact on Hospital Policy and Process. J Am Coll Radiol. 2010;7(8):573-81.

46. Pluimers DJ, van Vliet EJ, Niezink AG, van Mourik MS, Eddes EH, Wouters MW, Tollenaar RA, van Harten WH. Development of an instrument to analyze organizational characteristics in multidisciplinary care pathways; the case of colorectal cancer. BMC Res Notes. 2015;8:134

47. Raab SS, Grzybicki DM, Condel JL, Stewart WR, Turcsanyi BD, Mahood LK, Becich MJ. Effect of lean method implementation in the histopathology section of an anatomical pathology laboratory. J Clin Pathol. 2008;61(11): 1193-9.

48. Venkateswaran S, Nahmens I, Ikuma L. Improving healthcare warehouse operations through 5S. IIE Transactions on Healthcare Systems Engineering. 2013;3(4):240-53.

49. Culig MH, Kunkle RF, Frndak DC, Grunden N, Maher TD, Magovern GJ. Improving Patient Care in Cardiac Surgery Using Toyota Production System Based Methodology. Ann Thorac Surg. 2011;91(2):394-400.

50. Vermeulen MJ, Stukel TA, Guttmann A, Rowe BH, Zwarenstein M, Golden B, Nigam A, Anderson G, Bell RS, Schull MJ, et al. Evaluation of an emergency department lean process improvement program to reduce length of stay. Ann Emerg Med. 2014;64(5):427-38.

51. Ahmed S, Abd Manaf NH, Islam R. Measuring Lean Six Sigma and quality performance for healthcare organizations. Int J Qual Serv Sci. 2018;10(3): 267-78.

52. Boronat F, Budia A, Broseta E, Ruiz-Cerda JL, Vivas-Consuelo D. Application of Lean Healthcare methodology in a urology department of a tertiary hospital as a tool for improving efficiency. Actas Urol Esp. 2018;42(1):42-8.

53. Dickson EW, Anguelov Z, Vetterick D, Eller A, Singh S. Use of lean in the emergency department: a case series of 4 hospitals. Ann Emerg Med. 2009; 54(4):504-10.

54. Holden RJ, Eriksson A, Andreasson J, Williamsson A, Dellve L. Healthcare workers' perceptions of lean: A context-sensitive, mixed methods study in three Swedish hospitals. Appl Ergon. 2015;47:181-92.
55. Lee JY, McFadden KL, Gowen CR. An exploratory analysis for Lean and Six Sigma implementation in hospitals: Together is better? Health Care Manag Rev. 2018;43(3):182-92.

56. Poksinska BB, Fialkowska-Filipek M, Engstrom J. Does Lean healthcare improve patient satisfaction? A mixed-method investigation into primary care. BMJ Qual Saf. 2017;26(2):95-103.

57. Simons P, Backes H, Bergs J, Emans D, Johannesma M, Jacobs M, Marneffe $W$, Vandijck D. The effects of a lean transition on process times, patients and employees. Int J Health Care Qual Assur. 2017;30(2):103-18.

58. van Lent WA, Goedbloed N, van Harten WH. Improving the efficiency of a chemotherapy day unit: applying a business approach to oncology. Eur J Cancer. 2009;45(5):800-6.

59. Van Vliet EJ, Bredenhoff E, Sermeus W, Kop LM, Sol JC, Van Harten WH. Exploring the relation between process design and efficiency in highvolume cataract pathways from a lean thinking perspective. Int J Qual Health Care. 2011;23(1):83-93.

60. New S, Hadi M, Pickering S, Robertson E, Morgan L, Griffin D, Collins G, Rivero-Arias O, Catchpole K, McCulloch P. Lean Participative Process Improvement: Outcomes and Obstacles in Trauma Orthopaedics. Plos One. 2016;11(4):13.

61. Robertson E, Morgan L, New S, Pickering S, Hadi M, Collins G, Arias OR, Griffin D, McCulloch P. Quality Improvement in Surgery Combining Lean Improvement Methods with Teamwork Training: A Controlled Before-After Study. Plos One. 2015;10(9):13.

62. leraci S, Digiusto E, Sonntag P, Dann L, Fox D. Streaming by case complexity: evaluation of a model for emergency department Fast Track. Emerg Med Australas. 2008;20(3):241-9.

63. Allaudeen N, Vashi A, Breckenridge JS, Haji-Sheikhi F, Wagner S, Posley KA, Asch SM. Using Lean Management to Reduce Emergency Department Length of Stay for Medicine Admissions. Qual Manag Health Care. 2017; 26(2):91-6.

64. Kaplan RS, Norton DP. The Balanced Scorecard -Measures That Drive Performance. Harvard Business Review 1992(January-February):71-79.

65. Baldrige Performance Excellence Program: Baldrige Criteria Commentary (Health Care). https://www.nist.gov/baldrige/baldrige-criteria-commentaryhealth-care. Accessed 15 Jan 2020.

66. Arah OA, Westert GP, Hurst J, Klazinga NS. A conceptual framework for the OECD Health Care Quality Indicators Project. Int J Qual Health Care. 2006;18: $5-13$.

67. Koch HCH. Implementing and Sustaining Total Quality Management in Health Care. Harlow: Longman; 1992.

68. Veillard J, Champagne F, Klazinga N, Kazandjian V, Arah OA, Guisset A-L. A hospital performance assessment framework for hospitals the WHO regional office for Europe PATH project. Int J Qual Health Care. 2005;17(6):487-96.

69. Campbell SM, Roland MO, Buetow SA. Defining quality of care. Soc Sci Medicine. 2000;51:1611-25.

70. Health Catalyst. A Framework for High-Reliability Organizations in Healthcare. https://www.healthcatalyst.com/insights/high-reliability-organiza tions-in-healthcare-framework. Accessed 15 Jan 2020.

71. Evans DB, Tan-Torres Edejer T, Lauer J, Frenk J, Murray CJL. Measuring quality: from the system to the provider. Int J Qual Health Care. 2001;13(6): 439-46.

72. The European Foundation for Quality Management. EFQM Model. https:// www.efqm.org/index.php/efam-model/download-your-free-short-copy-ofthe-efam-model/. Accessed 16 Jan 2020.

73. Moraros J, Lemstra M, Nwankwo C. Lean interventions in healthcare: do they actually work? A systematic literature review. Int J Qual Health Care. 2016;28(2):150-65.

74. Deblois S, Lepanto L. Lean and Six Sigma in acute care: a systematic review of reviews. Int J Health Care Qual Assur. 2016;29(2):192-208.

75. Persis DJ, Sunder SA, Sreedharan MVGR, Saikouk VR. T: Improving patient care at a multi-speciality hospital using lean six sigma. Prod Plan Control 2020:1-19.

\section{Publisher's Note}

Springer Nature remains neutral with regard to jurisdictional claims in published maps and institutional affiliations. 